\title{
How Mobile Game Startups Excel in the Market
}

\author{
Maryam Roshan \\ Aalto University \\ maryam.roshan@aalto.fi
}

\author{
Virpi Kristiina Tuunainen \\ Aalto University \\ virpi.tuunainen $@$ aalto.fi
}

\author{
Riitta Hekkala \\ Aalto University \\ riitta.hekkala@,aalto.fi
}

\begin{abstract}
This interpretive grounded theory study explains how the early-stage mobile game startups excel in the market after releasing their apps. The data was collected by interviewing 20 startups in an accelerator operated by a platform owner. Our model shows that the startups follow an experimentation approach that allows for discovery of areas of improvement as well new potential markets. They monitor the performance of their games in order to better understand how to excel in the market. Accordingly, they continuously improve their games and expand to new markets to meet their success objectives despite the possible restraints imposed on them by the platform owner and available analytics tools. Our study enriches the existing literature on mobile app development by startups, their success, and how the platform owner through the accelerator can affect the startups in succeeding.
\end{abstract}

\section{Introduction}

Mobile application (app) platforms have enabled a large number of third-party application (app) developers to create and distribute their mobile apps to the smartphone users with economic motivations [9]. They can distribute their apps through the digital market places, also called "app stores". Consequently, many types of apps are available on the app stores, with games comprising the largest category [17].

In spite of the opportunities, the app developers face some challenges in working on the platforms. They are responsible for the sales of their apps in addition to their technical development [9]. This requires them to have both technical and business knowledge about the markets, users, mobile devices and platforms at a global scale [1]. Moreover, they need to adhere to the rules of the platform owner regarding the platform control and app store design and mechanisms [9] [24].
Many of the app developers are independent startups [24] and need to cope with the lack of experience and shortage of resources in designing their products, markets and business models in a way to quickly scale up [22]. Mobile game startups face some context-specific challenges as well, due to the nature of their product and the more intense competition in the game category compared with other apps [32]. Game players are heterogenous in their expectations, and may not be able to define exactly what they want in advance [15]. Because the players have a great number of alternative games to choose from, they are not willing to wait long for any problems in a game to be fixed [32]. Moreover, games have the highest chance to attract the users and get on top ranking lists right upon their release time [31]. Creating a game with appeal to mass market and the ability to attract users and encourage them to continue playing is critical for the game developers.

Generally, to cope with market uncertainties and to avoid investing in a software product with little or no market appeal, startups are advised to follow the experimentation approach in their product development according to the lean principles [25]. They develop the products in iterations by measuring and learning from the users' feedbacks along the development period and adjusting the product accordingly. However, in the highly competitive global app market, the developers gain access to their users only after publishing the app on the platform [1], and that coincides with the time of the highest chance of receiving publicity and consequently, the app getting downloaded [31]. Therefore, it is critical for the app developers to define, on one hand, what needs to be offered at the launch time so that the already attracted users are not lost, and on the other hand, what can be experimented with and adapted to the users' expectations and the market.

To accelerate the market adaptation of their app, some startups participate in business accelerator programs to receive funding and training [4]. Some accelerators are affiliated with a company and called "corporate accelerators" [23]. Despite the mutual benefits, there can be some conflicts of interest related 
to objectives and values between the startups and the accelerator that need to be resolved [14].

The extant literature has discussed the challenges that app developers face in working on platforms in terms of competition and platform-owner's role. However, there is still very little research on understanding how the app developers cope with challenges in offering a product with appeal to users, and the attention is given to the development phase before publishing the apps (e.g. [24]). Hence, in this paper, we answer the research question of "How do the early-stage mobile game startups excel in the market?". Our focus is on the post-launch activities of the startups, and the role of the platform owner in shaping these post-launch activities for the startups.

Our findings are from an empirical study with 20 early-stage mobile game startups that participated in an accelerator program organized by a platform owner. We collected our data by semi-structured interviews with the startups and used a classic grounded theory methodology (GTM) (e.g. [19]). We contribute to the literature on software startups and how they experiment in finding the market-product fit to succeed, with particular focus on mobile game developers.

The remainder of the paper is organized as follows. In the next section, we present our literature review. Then we introduce the research setting and describe the research method. In the fourth section, we present the findings and continue in section five to discuss them in light of the literature. Finally, we conclude with a summary of the implications of study to theory and practice, and suggest avenues for future research.

\section{Literature Review}

Following the classic GTM tradition, we present the preliminary literature review [12] in this section. We reviewed the relevant streams of research to our context; i.e. mobile app development, software startups and business accelerators. The purpose of preliminary literature review is to have theoretical sensitivity about the existing knowledge without imposing the literature on data analysis. Later on, when concepts emerged from the empirical data, we conducted the theoretical integration by employing additional literature in the form of the extended literature [28] to discuss the concepts.

\subsection{Mobile application development}

Mobile application platforms connect multiple distinct groups of actors [2], including app users and app developers. These platforms allow third-party developers to create additional services and contents in the form of apps, and distribute them to the users through the app stores. The platform owners control the platforms with boundary resources through resourcing and securing mechanisms. Boundary resources are "the software tools and regulations that serve as the interface for the arm's-length relationship between the platform owner and the application developer" [8: 174]. Resourcing means extending the scope and diversity of the platform and supporting the app development and securing refers to controlling the developed apps to prevent the platform from infringing changes. The app developers may also engage in selfresourcing by designing their own boundary resources.

Operating on the platforms creates both opportunities and challenges for the developers. Platforms provide access to a global mass of mobile users to whom the apps can be distributed while sharing the possible app revenue with the platform owner. While many developers seek economic benefits by creating apps [9][2], the intense competition often forces them to offer their apps for free and to delay revenue for later. The developer might also choose to display advertisement in their apps or employ freemium model of revenue making by offering the app for free and encouraging the users to pay for additional features [1].

Furthermore, the market mechanism and the structure of the app stores with ranking lists are designed so that success leads to more success. Top positions on ranking lists have an impact on the number of downloads; yet, a large volume of downloads is required for a chance to get featured or listed (e.g. [2]). Meanwhile, the intense competition means that an app can stay featured or at top spots on the list only for a very short time (e.g. [31]) and the developer may lose the opportunity to succeed if they fail to capture the attention of the users in the short period of app store visibility. Generally, the need for additional marketing activities favors more resourceful firms [3]. For game developers, the challenges also include not knowing the exact expectations of the heterogenous users [15]; and the users' tendency to simply opt out a game in case of any problems rather than waiting for them to be fixed [32].

\subsection{Software startups and business accelerators}

Many of the mobile app developers are independent startups [24]. Software startups are defined as "those organizations focused on the creation of high-tech and innovative products, with little or no operating history, aiming to aggressively grow their business in highly scalable markets" [10: 585]. Startups are known to have limited resources in terms of knowledge, finance, 
and networking, but still need to be able to adapt quickly to the market in order to scale-up [22]. Failing in finding the product-market fit and a scalable business model is a common cause of failure for many startups [11].

The concept of lean startup was introduced to guide startups in creating the "right thing" for the customers [25]. Lean startups follow an experimentation approach following the build-measure-learn cycle (BML). They create a minimum viable products (MVP), test it with some customers, and adjust it according to the learning from the customers' feedbacks. MVP is a version of the product with minimum features and minimum development time allowing a complete round in the BML cycle. MVP must be complete enough to demonstrate the value that it is supposed to offer [18]. According to the results of the BML, the startup may stay on its current direction with the product or service or pivot to another direction.

Mobile app developers experiment in simultaneous or sequential way [5]. In the simultaneous approach the developer offers a portfolio of apps to the market and analyzes the market reaction, while in the sequential approach the developer offers one app and improve it gradually through updates. Even though simultaneous experimentation is advised by some guidelines to game developers and sequential experimentation to nongame developers [5], the scarce resources of game developers rarely allow for working on multiple games [16].

One way for the startups to compensate their lack of resources and knowledge of creating a right product for the market is to participate in an accelerator program. Accelerators are designed to expedite the growth of the startups by providing seed funding, training and mentoring, and networking opportunities over a short period of time [4]. Accelerators can be independent and provide service in return for equity stake in the startups, or be affiliated to a company by helping the startups to create products of interest for the company and/or build an ecosystem around the company [23]. The latter is referred to as "corporate accelerator". Accelerators provide numerous benefits to the startups in access to resources, markets, funding, and credibility in acquiring funding from investors [14]. However, in the case of the corporate accelerators, the differences in values and perceptions, mutual expectations, work practices and modes of operation between the startups and the corporate may cause conflicts between the company and the startups which requires resolution (e.g. [30]).

\section{Research setting and methodology}

We collected our empirical data by semi-structured interviews with 20 mobile game startups from 13 countries. The startups were working on their first commercial game and participating in the AppCampus accelerator program.

AppCampus was a corporate accelerator operating between 2012 and 2015. It was established as a partnership between a platform owner (Microsoft and formerly Nokia) and a university in Finland to fund and educate the mobile app developers for the Windows Phone (WP) platform. AppCampus staff selected the startups working on apps with potential for appealing the mass market. The funding was offered in exchange for 90 days of exclusivity period on the Windows Phone platform. In addition to the funding offered, some of the startups with apps deemed most promising were invited to participate in a two-week intensive training camp called AppCademy. During the whole lifetime of AppCampus, development of altogether over 300 apps were funded, and 160 app developers participated in AppCademy in eight batches.

The first author conducted the semi-structured interviews with the startup entrepreneurs during three AppCademy programs. She also observed most of the group sessions and interacted with the entrepreneurs and the AppCampus staff to create a shared understanding about the activities of entrepreneurs and the AppCampus. The interviews lasted between 30 to 60 minutes, they were recorded and transcribed, and field notes were taken after each interview. The interview themes addressed the background information about the startups (team, experience, roles), business model elements about their current and if any, previous apps (description, target audience, monetization, and success definition), and their interactions with AppCampus (experiences, learning). Collection of rich data by semi-structured interviews enabled us to comprehend and make sense of the activities of the startups (e.g. [12]).

We used the qualitative classic GTM for both the data analysis and theorizing (e.g. [12]). The open approach allowed by GTM was a suitable choice given the dearth of research on the activities of mobile app startups [8] and the role of the platform owner in their activities [24]. In addition, the classic approach of GTM allowed us to be flexible and creative in our conceptualization without imposing a priori concepts or framework to the data analysis [20].

We conducted three levels of open, selective and theoretical coding and allowed the concepts to genuinely arise from the rich empirical data. We read the interview transcripts line-by-line while assigning 
codes to the length of text that would help in understanding what was actually happening. [12] Examples of open coding are provided in Sections 4.1 4.5. The coding process was iterative. Initially 500 open codes were generated, but through multiple refining and merging by the GTM principle of constant comparison, they were reduced to 245 open codes. Saturation was reached when we started to see repetition of similar instances [12]. We grouped the open codes into 11 selective codes, five of which create our emergent core category 'Excelling in the Market' presented in this paper. We conducted theoretical coding by identifying the relationships between the selective codes while writing memos to assist the process. Finally, following the GTM, we conducted the theoretical integration by grounding the emergent core category with the use of the extended literature.

\section{Findings}

In this section, we present the core category Excelling in the market consisting of five selective codes: 1) Monitoring activities, 2) Post-launch activities, 3) Insights on the game performance, 4) Success with the game, and 5) Restraints. Table 1 summarizes the constructs of the core category by open and selective codes.

Table 1. Construction of 'Excelling in the market'

\begin{tabular}{|c|c|c|}
\hline Open codes & $\begin{array}{l}\text { Selective } \\
\text { Codes }\end{array}$ & Definition \\
\hline $\begin{array}{l}\text { Focusing on } \\
\text { analytics; } \\
\text { Monitoring } \\
\text { users' behaviors } \\
\text { in the game; } \\
\text { Monitoring } \\
\text { users' reviews }\end{array}$ & $\begin{array}{l}\text { Monitoring } \\
\text { activities }\end{array}$ & $\begin{array}{l}\text { Activities for } \\
\text { watching the } \\
\text { game market } \\
\text { performance } \\
\text { and user's } \\
\text { performance } \\
\text { inside the game }\end{array}$ \\
\hline $\begin{array}{l}\text { Improving the } \\
\text { game after } \\
\text { launch; Multi- } \\
\text { platform } \\
\text { activities }\end{array}$ & $\begin{array}{l}\text { Post-launch } \\
\text { activities }\end{array}$ & $\begin{array}{l}\text { Improvement } \\
\text { activities after } \\
\text { publishing the } \\
\text { game }\end{array}$ \\
\hline $\begin{array}{l}\text { Getting insight } \\
\text { into users' } \\
\text { behavior; } \\
\text { Getting } \\
\text { surprised by the } \\
\text { download } \\
\text { volume; Regret } \\
\text { about the past } \\
\text { activities }\end{array}$ & $\begin{array}{l}\text { Insights on } \\
\text { the game } \\
\text { performance }\end{array}$ & $\begin{array}{l}\text { Understandings } \\
\text { related to the } \\
\text { game market } \\
\text { performance of } \\
\text { and user's } \\
\text { behavior in the } \\
\text { game after } \\
\text { publishing the } \\
\text { game }\end{array}$ \\
\hline $\begin{array}{l}\text { Defining the } \\
\text { success by the }\end{array}$ & $\begin{array}{l}\text { Success with } \\
\text { the game }\end{array}$ & $\begin{array}{l}\text { What the } \\
\text { startups }\end{array}$ \\
\hline
\end{tabular}

\begin{tabular}{|c|c|c|}
\hline $\begin{array}{l}\text { download } \\
\text { volume; Defining } \\
\text { success by the } \\
\text { revenue volume; } \\
\text { Defining } \\
\text { success by } \\
\text { personal } \\
\text { achievements }\end{array}$ & & $\begin{array}{l}\text { consider as } \\
\text { success } \\
\text { definition for } \\
\text { their game }\end{array}$ \\
\hline $\begin{array}{l}\text { Restraints by } \\
\text { AppCampus; } \\
\text { Restraints by } \\
\text { the platform; } \\
\text { Restraints by } \\
\text { supporting tools }\end{array}$ & Restraints & $\begin{array}{l}\text { The limitations } \\
\text { that were } \\
\text { imposed on the } \\
\text { startups }\end{array}$ \\
\hline
\end{tabular}

Next, we will describe the selective codes and related open codes.

\subsection{Monitoring activities}

The selective code of Monitoring activities consists of three open codes: 1) focusing on analytics, 2) monitoring users' behaviors in the game, and 3) monitoring users' reviews.

Focusing on analytics describes how the startups used analytics tools that allowed them to collect data on the users and the market performance of their game. For this purpose, they mostly used free available tools such as Flurry and/or Google analytics. They collected various types of market-related data, such as number of downloads, uninstallments and active users, user retention rate, and demographic information (e.g. age, location, gender).

"We've got about 96 per cent males. So, it's good to know, like, what kind of audience you're targeting. So, yes, the geography, 'Where do people come from?"' (Startup I)

Monitoring users' behaviors in the game depicts how the startups monitored the game players' behaviors and activities. By observing the users' activities, insights could be gained on users' interests and challenges, and/or usage of the in-app-purchase features. The startups could use this information for their future game updates and strategizing.

"[We monitor] useful information, like, 'How many percentage the users complete?', 'How many levels?', 'In which point the users stop playing, and what could be the reason for that?'” (Startup N)

Monitoring users' reviews highlight the startups' attention to the reviews provided by the users and/or their star ratings. These user reviews helped the 
startups to better understand what their users cared about and what kind of challenges they had. The reviews also offered new ideas on how to extend and improve the game. It was mentioned that not all the reviews were necessarily meaningful or unbiased; however, most of the reviews could still be leveraged on.

"So, the languages I'm going to go [for localizing the game] is Spanish and French. I get many good reviews from the French; they really like it. [...] And Russia of course, because they want it." (Startup J)

\subsection{Post-launch activities}

The selective code of Post-launch activities is comprised of two open codes: 1) improving the game after launch, and 2) multi-platform activities.

Improving the game after launch reflects how the startups used the data gathered with analytics tools or by users' reviews to improve the game after its initial publishing. There were a number of reasons for the improvements, including the aims of increasing the user retention rate, creating more content for the game, tailoring the game to specific target markets, improving or implementing new monetization mechanisms, and fixing bugs.

"[We are] adjusting the game play, because now we found out at the beginning of the game is too hard, and then the ending is too easy. [...] We are [also] adding some enemies there and a few new mechanics" (Startup B)

Multi-platform activities relate to the startups' preparations to enter also other platforms after the 90day exclusivity period on the WP platform. Many of the startups considered preparing their games for other more competitive platforms already during the exclusivity period. Monitoring the performance of the game on the WP platform allowed them to see the strengths and weaknesses of their games and to improve them before entering other platforms. The additional platforms were chosen based on the potential of success and monetizing according to the game type.

"It's also an awesome way to soft-launch and get, ideally, a lot of publicity and a lot of downloads; and then make the iOS people wait for it. [...] We hope to play that down the line into a great iOS/Android launch by being like, 'Finally! The moment you've been waiting for!'” (Startup A)

\subsection{Insights on the game performance}

The selective code Insights on the game performance contains three open codes: 1) getting insight into the user's behavior, 2) getting surprised by the download volume, 3) regret about the past activities.

Getting Insight into Users' Behavior reflects the way the startups learned about the game performance, which could be different from what they had intended or expected. The differences were related to various aspects, such as the game play, effectiveness of monetizing, and the reviews.

"Actually, that's one of our problems, because there is not much incentive to purchase; because you can get almost everything for free" (Startup N)

Getting surprised by the download volume highlights difficulty to forecast the success of the game. In some occasions, the startups did not expect any large volume of download for their game when trying to do some experimentation for fun or learning purposes, but the game turned out to get downloaded a lot. In other occasions, the game was downloaded much less than anticipated.

"It was a cool game, but I put it for money, [...] and I was shocked that no one actually want to pay in the market." (Startup O)

Regret about the past activities is related to losing some opportunities to get downloads or monetizing because of some past activities. These were typically caused by lack of knowledge about the business side of game development, resulting in mistakes in, for example, selecting the target markets, marketing the game, localizing the game, and/or monetizing.

"[Our previous game was] totally free. Totally free! Very non-professional!" (Startup A)

\subsection{Success with the game}

The selective code Success with the game consists of three open codes: 1) defining success by the download volume, 2) defining success by the revenue volume, and 3) defining success by personal achievements.

Defining success by the download volume reflects the focus of the startups on a high volume of download as their first success measure. A common belief was that this would enable them create a good reputation 
and also be useful for possible future business on the WP platform or on other platforms.

"Our success will not be in terms of money. It will be in terms of downloads, because first of all we want to increase brand awareness. So, in reality, we're not waiting for money." (Startup M)

Defining success by the revenue volume relates to the attention of the startups on generating revenue from their games in order to survive in the game development business. However, revenue making was rarely the first priority and an immediate measure of success. Rather, for their first commercial game, the startups were more concerned about the minimum amount of income that would allow their survival than profit making.

"If we made enough money to make the other game [i.e. the next game]." (Startup P)

Defining success by personal achievements reflects some startups' focus on success in terms of their experimental endeavors and learning. These startups considered being able to finish the project and publish the game as their success measure. This measure was mostly mentioned by the startups who wanted to include innovative and experimental features in their games.

"The goal of this game for us is to see if we can make like those other storytelling games in the PC game market; to see if we can adapt it and figure out what's not working and figure out how we can fix it; to see if we can find a storytelling model that we can then launch other games with." (Startup A)

\subsection{Restraints}

The selective code Restraints is comprised of three open codes: 1) restraints by AppCampus, 2) restraints by the platform, and 3) restraints by the analytical tools.

Restraints by AppCampus is about the limitations imposed on the developers by AppCampus, mainly in terms of timing of different support activities, AppCampus' interests, and AppCampus' change of strategy. Overall, these restraints created some extra work as the startups needed to amend their games according to the accelerator's requirements. Some startups thought that the training would have been more useful earlier before launching the game. Also, some startups thought that the timing of funding was not necessarily helpful in hiring the right expertise at the time of need. In some cases, the goals of the startups were not in line with the success measures defined by the accelerator. While the accelerator training was focused on getting a high download volume, some startups had other objectives for their games. Also, some strategies of the accelerator were changed along the modifications to the platform's strategies, creating additional work for the startups.

"Then a layer of the AppCampus are the talks and the support and everything. I think it's a little different for us because we are definitely in the art game camp." (Startup C)

Restraints by the platform refers to the limitations and/or strategies of the WP platform that were imposed on the startups. They were related to the platform owner's preferences, and the limitations of the app store. The startups were required by the platform to design their game according to the mobile device hardware specifications and if developers did not follow the rules, their apps were not approved by the quality assurance team. Furthermore, the startups were not able to contact the users directly through the app store and had to find other ways of direct contacts. Further, some startups faced problems with the app store limitations in terms of suitable category for the game genre.

"On Windows Phone, you shouldn't have a back button, because every phone has a hardware back button. So, they didn't want it. We would have wanted it, because it's better for users; but they actually forced us to remove it." (Startup N)

"I think that they should make an option to answer to users. [...] In the game, there is a support button they [i.e. the users] press and they can send us an email." (Startup H)

Restraints by the supporting tools reflects the limitations of the analytical tools or the development tools that the startups were using in developing or monitoring their games. The frequent changes with both the technologies and the platform created some incompatibility issues between the platform and the third-party development tools. In addition, the analytical tools used by the startups did not always provide the exact data the startups desired and sometimes they had to combine several tools to capture the data needed.

"The Unity integrations of the Windows Phone exporter are still very new. So, we've been hung up a few times. We find a bug, [...] and then, we have to wait for Unity to fix it." (Startup C) 
"I get numbers out of Flurry and Google Analytics, and they're different." (Startup F)

\section{Discussion}

The next step is to conduct the theoretical coding by drawing the relationship between the selective codes [12] and finally to present the theoretical integration by using the extended literature [28].

\subsection{Relating the selective codes}

Next, we present our model (Figure 1) to explain the relationships between the selective codes as the starting point for theorizing about how the startups excel in the market.

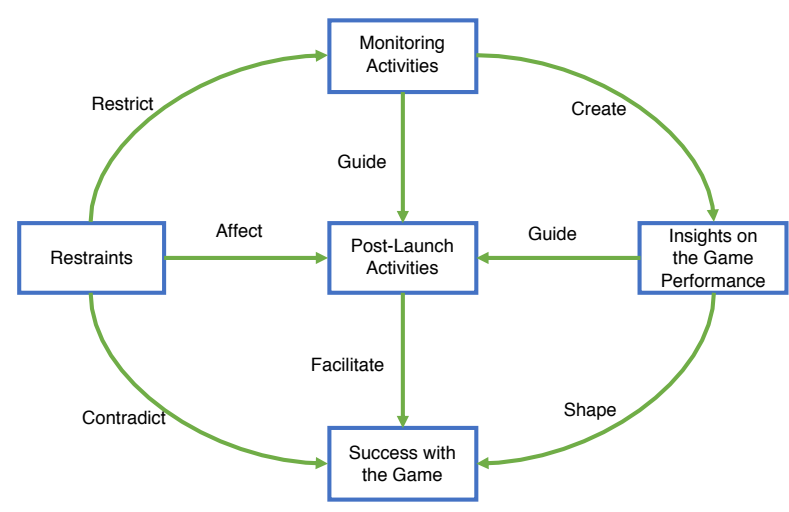

Figure 1. Excelling in the market

After releasing the game, the startups begin monitoring the market with the help of analytical tools and the users' reviews to learn how their games are received. By understanding the strengths and weaknesses of their games, the startups can gain validated insight about the performance of their games. These insights assist the startups in setting realistic success objectives for their games. Additionally, they can plan their multi-platform activities and increase the quality of their games through post-launch activities. Game quality is enhanced by increasing the user retention, offering more content, improving the existing and applying new monetization models, and localizing the game for different target markets. The post-launch activities are facilitated by the monitoring activities through the collection of game analytics and users' review data. In turn, the post-launch activities facilitate achieving the defined success, typically in terms of download volume, to pave the way to future revenue making.

Nevertheless, there are some restraints that affect the post-launch activities: some analytical tools fail to provide the startups with their desired data; the limitations set by the platform owner regarding direct contact with users can restrict the startups' monitoring activities; and, the startups may need to engage in some additional work in their post-launch activities in face of changes in the platform strategies, lack of timely support from the platform, or app store limitations. Meanwhile, the focus on download volume emphasized in the AppCampus training and support, might not be fully aligned with some success objectives of the startups, particularly those who are not seeking high download volume immediately.

\subsection{Theoretical integration - grounding the concepts}

The findings of this study confirm that early-stage startups with their limited resources work on one game at a time rather than on multiple games [16] and that startups follow the sequential experimentation approach to improve their games after their release (cf. [5]).

Moreover, the findings are in line with earlier studies indicating that mobile game startups develop their games based on their founders' own experiences [21] and beta-testing in small groups. However, there can be unexpected problems and challenges after publishing the games. Our findings confirm the unpredictability of the game players identified in earlier research [15].

5.2.1. Using continuous experimentation. To reduce the uncertainties related to the market reactions to a new software product, extant literature emphasizes the importance of continuous experimentation [7]. The type of data collected from users has been found to be different in various stages of the product development (e.g. [21]). In early stages, startups use qualitative user inputs that are deliberately shared by the users. Then, in later stages of the development, the users' inputs are collected in large quantitative data sets without the users' control. Our findings show that after releasing the games, the startups exploited both qualitative and quantitative data. Besides collecting the data by game analytics, the users' reviews were seen as an important source of improvement ideas and strategy setting. This confirms the role of users as an invaluable asset for the mobile game startups and emphasizes the importance of the human capital in building the business models for software companies [29]. Exploitation of users' feedbacks is not limited to the app ideation as discussed in an earlier study on mobile app developers [24], but is extended to the after-release improvements regarding the app artefact and markets. The possibility to receive and exploit the users' reviews on the app stores creates a ground for open-ended 
experimentations for the software startups without any preset assumptions to be validated [7]. Instead, it allows the startups to discover areas of improvement as well as new potential markets.

Startups considered offering their games as a service with freemium model of revenue making (e.g. [13]). Along the lines of this thinking, we can consider the widely used SERVQUAL measure of quality in evaluating the quality of the startups' games (e.g. [13]). With SERVQUAL, the quality of a game service is assessed in five areas: tangible features in the game, creating empathy with users, assuring the users to trust the developer, being responsive towards the users, and reliability of the game in terms of technical design. The findings show that the improvements made to the released games were in terms of creating more tangible elements (e.g. extend the content and monetization mechanisms) and increasing empathy with users (adding customized in-app-purchase items and localization). Meanwhile, the reliability of the games and the assurance were already proofed upon launch by having the approval of the accelerator's quality assurance team before release. Nevertheless, the tangible element of game complexity require special attention before the game is released. If the users find the game too complex and difficult to play, they may choose not to play it at all [16].

5.2.2. Scaling up. In the extant lean startup literature, the main concern for the startups is to find the correct product-market fit, but the scaling of the product to markets is not addressed (e.g. [25]). The earlier literature considers the product and market evolution gradual, so that the product is delivered to an existing set of early adopters to be proofed before extending the customer segment [19].

The startups in our data set released their games on the platform at a global level. With this approach, they targeted all potential users at the outset, and collected global data to learn about specific markets with potential to invest more. The mobile game startups exploited the possibility offered by the platform to immediately scale to global markets at the release time. Accordingly, they could set their objectives of investment in potential markets after getting to know them better through game analytics and users' reviews. It is worth highlighting the fact that because of the mentoring by the accelerator and the quality assurance approval, the startups were already quite certain about the performance quality of their games. In the absence of more formal quality assurance, startups may want to deliver their games first to a test market on the platform, for example a specific geographic area, to make sure of its performance quality [15].
5.2.3. Coping with the platform owner rules. The startups both accommodated to the rules of the platform owner and resisted them, confirming the existing literature [6]. The startups were accommodating to the platform rules in areas where they had no power against the platform securing efforts. An example of this is having to change the game design to be compatible with the mobile device according to the platform owner's wish. However, wherever they could, they sought ways to meet their objectives through self-resourcing [8]. For example, to increase their responsiveness towards the users (a measure in SERVQUAL), they resisted the platform restrictions by designing a contact channel inside the game for direct contact with the players. Moreover, to cope with the limitations of the available analytics tools, the startups created their own tools to collect their desired data.

\subsection{Implications to theory}

Our study contributes to the literature on software startups developing mobile games by explaining how they experiment to find the fit between the product and market(s) in three ways. Firstly, we answer the call for research on when and how experimentation is done in software startups [7]. Contrary to earlier research [5], our study shows how the early-stage game startups used sequential experimentation after the release of their app to compensate for the shortage of financial resources and knowledge about the markets. Sequential experimentation process was their means to identify the areas for improvement and expanding the markets.

Secondly, we contribute to the literature on the use of the game analytics for early-stage startups. We extend the contributions of Koskenvoima and Mäntymäki [15] with our larger set of studied startups. In particular, we highlight the importance of users' qualitative data, which has not been addressed before. Even though the more established game producers obviously have more resources to be spent on game analytics, our findings show the value and cruciality of using game analytics also in early-stage startups in developing their business and excelling in the market. While the heterogeneity of users' expectations is considered to cause difficulties for game developers [5], our findings show that the startups can take advantage of this heterogeneity by taking an experimentation approach and discovering the right target markets for their games with the help of game analytics.

Thirdly, we contribute to the literature on the relationships between platform owners and startups, taking place through both the platform-owned accelerator and the platform structure. We show how 
the accelerator assumed a boundary resource role [26] with its quality assurance team imposing controlling rules and regulations on the startups. Accordingly, the startups, either complied with or resisted the rules. Their compliance or resistance was guided by their quality objectives for their game as a service.

\subsection{Implications to practice}

Our study offers some practical implications for game developer startups. The startups should concern the unpredictability and heterogeneous demands of game players [15][32], and take advantage from them. Confirming the existing literature (e.g. [27]), the business model of the game startups should focus on the notion of fast 'adaptability'. The game developers should be aware that collecting the performance data and users' reviews, and maneuvering by data lead is a critical part of their business model. The available free or low-cost analytics tools can work adequately to serve the purpose of monitoring and adapting. The monitoring does not solely apply to enriching the game content but should be used to guide the startups in their market investments and strategies through localization. The experimentation approach suggests to initially offer the game in English or with a few localization languages for famous game markets, and then to find the high potential markets by monitoring the game analytics and localize the game for them.

\section{Conclusion}

The main contribution of this GTM study is the model (Figure 1) and our theorizing to explain how the early-stage game developers excel in the market after publishing their apps. Our model explains the startups' strategy for exploiting the platform-based context to take advantage of the heterogenous user demands and to create more content and empathy with potential users, while accommodating and resisting to the boundary resources.

Although the Windows Phone platform has practically ceased to exist, the findings of our study can be still relevant in understanding the early-stage startup activities in terms of finding the market-product fit. While the studied startups were influenced by the platform owner through its accelerator program, the issues they faced were not specific to the platform or the accelerator but can be considered emblematic of any setting where startups are working under the platform owner's rules, with or without an accelerator. We believe that the process of experimentation as explained in our study can apply to any early-stage mobile game developer startups. We do acknowledge, however, that competition on Windows Phone platform that our study focused on was much weaker than on the larger (and still extant) iOS and Android platforms. Indeed, an interesting avenue for future research would be to study the early-stage startups in these more mature platforms and to identify the differences in their strategies and processes. Moreover, the focus of this study was on early-stage startups that suffer from lack of resources and cannot afford to invest in developing multiple apps simultaneously. Therefore, another possible direction for future research would be to study if the experimentation approach as described in this study applies to the more established startups and firms with more ample resources. As the GTM leaves room for modification of the model upon appearance of new data [12], future research will determine if our theorizing about how startups excel in the market applies beyond the context of the study reported in this paper.

\section{References}

[1] Bergvall-Kåreborn, B., and D. Howcroft, “'The Future's Bright, the Future's Mobile': a Study of Apple and Google Mobile Application Developers", Work, Employment \& Society, 2013, pp. 1-18.

[2] Bergvall-Kåreborn, B., and D. Howcroft, "The Apple Business Model: Crowdsourcing Mobile Applications", Accounting Forum 37(4), 2013, pp. 280-289.

[3] Bresnahan, T.F., J.P. Davis, and P. Yin, "Economic Value Creation in Mobile Applications", In A.B. Jaffe and B.F. Jones, eds., The Changing Frontier: Rethinking Science and Innovation Policy. University of Chicago Press, 2015, 233286.

[4] Cohen, S., and Y. Hochberg, "Accelerating Startups: The Seed Accelerator Phenomenon”, SSRN 2418000, 2014, pp. $1-16$.

[5] Davis, J.P., Y. Muzyrya, and P. Yin, Experimentation Strategies and Entrepreneurial Innovation: Inherited Market Differences in the iPhone Ecosystem, 2014.

[6] Eaton, B., S. Elaluf-Calderwood, C. Sørensen, and Y. Yoo, "Distributed Tuning of Boundary Resources: The Case of Apple's iOS Service Systems", MIS Quarterly 39(1), 2015, pp. 217-243.

[7] Fagerholm, F., A. Sanchez Guinea, H. Mäenpää, and J. Münch, "The RIGHT Model for Continuous Experimentation", Journal of Systems and Software 123, 2017, pp. 292-305.

[8] Ghazawneh, A., and O. Henfridsson, "Balancing Platform Control and External Contribution in Third-party

Development: The Boundary Resources Model", Information Systems Journal 23(2), 2013, pp. 173-192. 
[9] Ghazawneh, A., and O. Mansour, "Value Creation in Digital Application Marketplaces: A Developers' Perspective", Thirty Sixth International Conference on Information Systems, Fort Worth 2015, (2015), 1-17.

[10] Giardino, C., N. Paternoster, M. Unterkalmsteiner, T. Gorschek, and P. Abrahamsson, "Software Development in Startup Companies: The Greenfield Startup Model", IEEE Transactions on Software Engineering 42(6), 2016, pp. 585604.

[11] Giardino, C., X. Wang, and P. Abrahamsson, "Why Early-Stage Software Startups Fail: A Behavioral Framework", Lecture Notes in Business Information Processing 182 LNBIP, 2014, pp. 27-41.

[12] Glaser, B.G., Doing Grounded Theory: Issues and Discussions, Sociology Press, 1998.

[13] Hamari, J., K. Alha, S. Järvelä, J.M. Kivikangas, J. Koivisto, and J. Paavilainen, "Why do Players Buy in-Game Content? An Empirical Study on Concrete Purchase Motivations", Computers in Human Behavior 68, 2017, pp. 538-546.

[14] Kohler, T., "Corporate Accelerators: Building Bridges Between Corporations and Startups", Business Horizons 59(3), 2016, pp. 347-357.

[15] Koskenvoima, A., and M. Mäntymäki, "Why Do Small and Medium-Size Freemium Game Developers Use Game Analytics?", Open and Big Data Management and Innovation, (2015).

[16] Li, M., Q. Jiang, C.-H. Tan, and K. Wei, "Enhancing User-Game Engagement Through Software Gaming Elements", Journal of Management Information Systems 30(4), 2014, pp. 115-149.

[17] Merikivi, J., V. Tuunainen, and D. Nguyen, "What Makes Continued Mobile Gaming Enjoyable?", Computers in Human Behavior 68, 2017, pp. 411-421.

[18] Moogk, D.R., "Minimum Viable Product and the Importance of Experimentation in Technology Startups", Technology Innovation Management Review 2(March), 2012, pp. 23-26.

[19] Nguyen-Duc, A., S.M.A. Shah, and P. Ambrahamsson, "Towards an Early Stage Software Startups Evolution Model", Proceedings - 42nd Euromicro Conference on Software Engineering and Advanced Applications, SEAA 2016, 2016, pp. 120-127.

[20] Niekerk, J.C. Van, and G. Campus, "Glaserian and Straussian Grounded Theory: Similar or Completely Different?", Proceedings of the 2009 Annual Research Conference of the South African Institute of Computer Scientists and Information Technologists, (2009), 96-103.
[21] Olsson, H.H., and J. Bosch, "Towards Continuous Customer Validation: A Conceptual Model for Combining Qualitative Customer Feedback with...", Software Business. ICSOB 2015. Lecture Notes in Business Information Processing, vol 210, Springer, Cham (2015), 154-166.

[22] Paternoster, N., C. Giardino, M. Unterkalmsteiner, T. Gorschek, and P. Abrahamsson, "Software Development in Startup Companies: A Systematic Mapping Study", Information and Software Technology 56(10), 2014, pp. $1200-1218$.

[23] Pauwels, C., B. Clarysse, M. Wright, and J. Van Hove, "Understanding a New Generation Incubation Model: The Accelerator”, Technovation 50-51, 2016, pp. 13-24.

[24] Qiu, Y., A. Gopal, and I.-H. Hann, "Logic Pluralism in Mobile Platform Ecosystems: A Study of Indie App Developers on the iOS App Store", Information Systems Research, 2017, pp. 1-25.

[25] Ries, E., The Lean Startup: How Constant Innovation Creates Radically Successful Businesses, Penguin Group, London, 2011.

[26] Roshan, M., R. Hekkala, and V.K. Tuunainen, "Utilization of Accelerator Facilities in Mobile App Developer Startups", Twenty-Sixth European Conference on Information Systems (ECIS), (2018).

[27] Spiegel, O., P. Abbassi, M.P. Zylka, D. Schlagwein, K. Fischbach, and D. Schoder, "Business Model Development, Founders' social Capital and the Success of Early Stage Internet Start-ups: A Mixed-Method Study", Information Systems Journal 26(5), 2016, pp. 421-449.

[28] Urquhart, C., H. Lehmann, and M.D. Myers, "Putting the 'theory' back into grounded theory: Guidelines for grounded theory studies in information systems", Information Systems Journal 20(4), 2010, pp. 357-381.

[29] Vanhala, E., and M. Saarikallio, "Business Model Elements in Different Types of Organization in Software Business", International Journal of Computer Information Systems and Industrial Management Applications 7, 2015, pp. 139-150.

[30] Weiblen, T., and H.W. Chesbrough, "Engaging with Startups to Enhance Corporate Innovation", California Management Review 57(2), 2015, pp. 66-90.

[31] Yi, J., Y. Lee, and S. Kim, "Determinants of Growth and Decline in Mobile Game Diffusion", Journal of Business Research, 2017, pp. 0-10.

[32] Yin, P.-L., J.P. Davis, and Y. Muzyrya, "Entrepreneurial Innovation: Killer Apps in the iPhone Ecosystem", American Economic Review 104(5), 2014, pp. 255-259. 